\title{
EL LEGADO IMAGINERO DE MANUEL MARÍA ZÚÑIGA RODRÍGUEZ
}

The imaginary legacy of Manuel María Zúñiga Rodríguez

\author{
Luis Carlos Bonilla Soto \\ Universidad Estatal a Distancia, Costa Rica \\ Seminario Nacional Ntra. Sra. de los Ángeles, Costa Rica \\ Icbonillasoto@gmail.com
}

Recibido: $16-05-2018$

Aprobado: 28-05-2018

\begin{abstract}
Luis Carlos Bonilla Soto es Licenciado en Sociología por la Universidad de Costa Rica. Investigador en los departamentos de Arte Sacro y Piedad Popular de la Curia Metropolitana de San José, Costa Rica. Bonilla es docente en la Universidad Estatal a Distancia y en el Seminario Nacional Ntra. Sra. De los Ángeles.
\end{abstract}

\section{RESUMEN}

El artículo describe el acervo escultórico realizado por el artista costarricense Manuel María Zúñiga Rodríguez, custodiado por la Arquidiócesis de San José, con miras a identificar su ubicación y cuantificar los temas religiosos representados por este imaginero.

Palabras clave: escultura; imaginería; arte sacro costarricense; Manuel María Zúñiga Rodríguez

\section{ABSTRACT}

This article describes the sculptural collection made by the Costa Rican artist Manuel María Zúñiga Rodríguez. This collection is guarded by the Archdiocese of San José. The aim of this work is to identify its location and to quantify the religious themes represented by this artist.

Keywords: sculpture; imaginery; Costa Rican sacred art; Manuel María Zúñiga Rodríguez

\section{1. ¿Dónde están las más de dos mil obras de Zúñiga?}

Manuel María Zúñiga Rodríguez, el escultor, el imaginero, el artista, es mencionado recurrentemente en los libros de historia del arte en Costa Rica como un personaje importante que, desde su taller de imágenes religiosas, dio paso a una generación de escultores prominentes en el país. Pero hasta ahí su referencia. 
Basta mirar como ejemplo, la ficha \#43 del guión museográfico de la exhibición "El Arte en la Evangelización", realizada en conmemoración del V centenario de la evangelización, en la cual se hace una referencia biográfica breve de Zúñiga, indicando que fue el escultor imaginero que más alto prestigio alcanzó en el siglo $\mathrm{XX}$, pero no se profundiza más allá de esto.

Él se ha convertido en una referencia ineludible: es el padre de "Paco", Edgar y Franklin; en su taller se formaron y trabajaron Juan Rafael Chacón, Juan Manuel Sánchez y Néstor Zeledón Varela, entre otros renombrados artistas. Pero ¿qué se dice de su obra? ¿quién ha estudiado a profundidad su legado? ¿Están identificadas las más de dos mil obras que afirmara Norma Loaiza (cifra señalada por la periodista, a partir de una entrevista realizada en 1978)?

Hasta la fecha, cuando se hacen reportajes sobre arte sacro en Costa Rica él es mencionado de manera preponderante. No obstante, en los intentos de profundizar en la vasta obra de este artista, a partir de la revisión bibliográfica y documental, se hallan muchas referencias a su nombre, pero muy poca cuantificación y análisis al respecto. Las fuentes que hablan con mayor profundidad de su trabajo son muy limitadas y no identifican de manera precisa más que diez esculturas salidas de sus manos. Lo anterior, sin considerar las "verdades" afirmadas por quienes se califican como sabedores de la materia, pero que no aportan respaldos metodológicos que permitan corroborar a ciencia cierta dicha información.

A todo esto se suma un gravísimo problema: la invisibilización de este artista en el ámbito académico. Un ejemplo de ello se hace patente en el texto denominado "Recorrido por la historia de las artes visuales patrimoniales costarricenses" escrito por Ana Mercedes González Kreysa, para la obra Acervo Turístico Cultural Costarricense de la antropóloga Giselle Chang Vargas. En dicho texto, aunque se nombra a su tío abuelo Manuel "Lico" Rodríguez Cruz y a su hijo Francisco "Paco" Zúñiga, el nombre de Manuel figura ausente, quitándole méritos como artista y como mentor de múltiples artistas en el país (2016, p. 489).

Ante este panorama, surge la necesidad de realizar la identificación de las obras de Manuel María Zúñiga Rodríguez metodológicamente. El ejercicio de identificación se sustenta en el trabajo de levantamiento de las fichas de registro de inventario de todos los bienes artísticos e históricos de la Arquidiócesis de 
San José, elaborado entre el 2007 y el 2014 por Luis Carlos Bonilla Soto y Luis Gerardo Santamaría Rivera.

Por lo anterior, este artículo tiene por objetivo dejar constancia de las obras de este imaginero que han logrado ser identificadas, así como enlistar las posibles obras de su autoría, con el objetivo de propiciar estudios pormenorizados del legado patrimonial que este maestro aportó al país, tanto en lo que se refiere a las obras creadas como al conocimiento aportado a las generaciones de escultores que le sucedieron en Costa Rica.

\section{Cuando el artista deja de ser referente: dificultades metodológicas}

Cuenta la tradición oral que en una ocasión fue llamado don Manuel María Zúñiga Rodríguez, a la iglesia parroquial de San Miguel de Escazú, para que revisara una imagen de la Virgen María para dejarla "bonita", es decir, retocarla. Al toparse el imaginero con la Inmaculada Concepción policromada por Pedro Gallardo en Guatemala en el siglo XIX, exclamó: "Ese pecado yo no lo cometo".

Paradójicamente, el pecado que no cometió Zúñiga con la obra de Gallardo1, sí la cometieron distintas personas con un buen número de obras únicas que talló en madera y vació en yeso este prolífico artista costarricense.

Es lamentable que en Costa Rica la restauración como disciplina asociada a la conservación y facilitación de la lectura de obras de arte, es mal entendida en la mentalidad de las mayorías, ya que se asocia a meras técnicas para remozar bienes muebles e inmuebles. Esto ha provocado que las obras de un sin número de artistas hayan sido intervenidas de modo tal que se han irrespetado estilos, técnicas, significados e incluso firmas plasmadas por los maestros y maestras creadoras.

Aunado a lo anterior, en lo relativo a la imaginería, muchos siguen afirmando que las auténticas obras de arte fueron confeccionadas en el exterior. Lo cual ha llevado incluso a señalar erróneamente que varias obras de don Manuel Zúñiga son obras traídas a Costa Rica desde Guatemala o España.

\footnotetext{
1 Sin embargo, es sabido que la obra del Cristo Yaciente tallado por don Manuel "Lico" Rodríguez, maestro imaginero y familiar suyo, fue modificado por él, por encargo de las autoridades catedralicias.
} 
Dichosamente, esta visión en los gremios artísticos y académicos ha ido cambiando de forma paulatina gracias a trabajos de investigadores y a esfuerzos institucionales, pero queda mucho camino por andar para desmentir y aclarar discursos en torno al arte en Costa Rica.

Este estudio de las obras de Zúñiga parte del trabajo de inventario de todas las obras artísticas e históricas del acervo patrimonial de la Iglesia Arquidiocesana, de una revisión sistemática de las esculturas, su documentación por medio de fotografías, descripciones y medidas, así como de la revisión documental referente a las mismas.

Los criterios de identificación que permiten afirmar la autoría al taller de Zúñiga, son:

1. Presencia de la firma.

2. Respaldo de noticias de prensa de la época en que se creó una obra específica.

Por otra parte, los criterios empleados para identificar posibles obras provenientes de este taller de imaginería, pero que requieren una triangulación de la información para ser corroboradas fueron:

1. Identificación de los territorios y lugares de culto donde existe mayor número de obras para establecer relaciones entre el imaginero y el número de encargos realizados por las comunidades a este.

2. Análisis comparativo, por medio del cual se identificaron rasgos en la línea de confección a partir de la observación detenida de aspectos anatómicos, tales como: rostros, manos y pies, así como detalles de los vestidos. Esto comparado a partir de las distintas temáticas que representan las obras.

Como bien afirma Reymundo Méndez:

Para empezar a distinguir la obra del imaginero se hace absolutamente necesario someterse a un entrenamiento visual, basado en un estudio riguroso de observación directa que de ninguna manera este puede ser apresurado. Se debe comparar un número suficiente de obras para encontrar las características comunes y aislarlas de las variantes. (1997, p.14). 
Cabe acotar que, en el momento de realizar las observaciones del acervo fotográfico y establecer comparaciones, se omitió valorar rasgos pictóricos, pues un $84 \%$ de las obras analizadas no conservan su policromía original, lo que tiende a provocar confusión por los rasgos que puede generar el uso de una paleta de color distinta a la que se manejó en el taller del artista originalmente.

Además, por la lógica interna del taller de este imaginero, resulta sumamente difícil determinar cuál de los ayudantes del maestro intervinieron en la realización de una u otra obra, por lo cual, se identifican todas las obras salidas del taller con don Manuel indistintamente de las individualidades detrás de cada una.

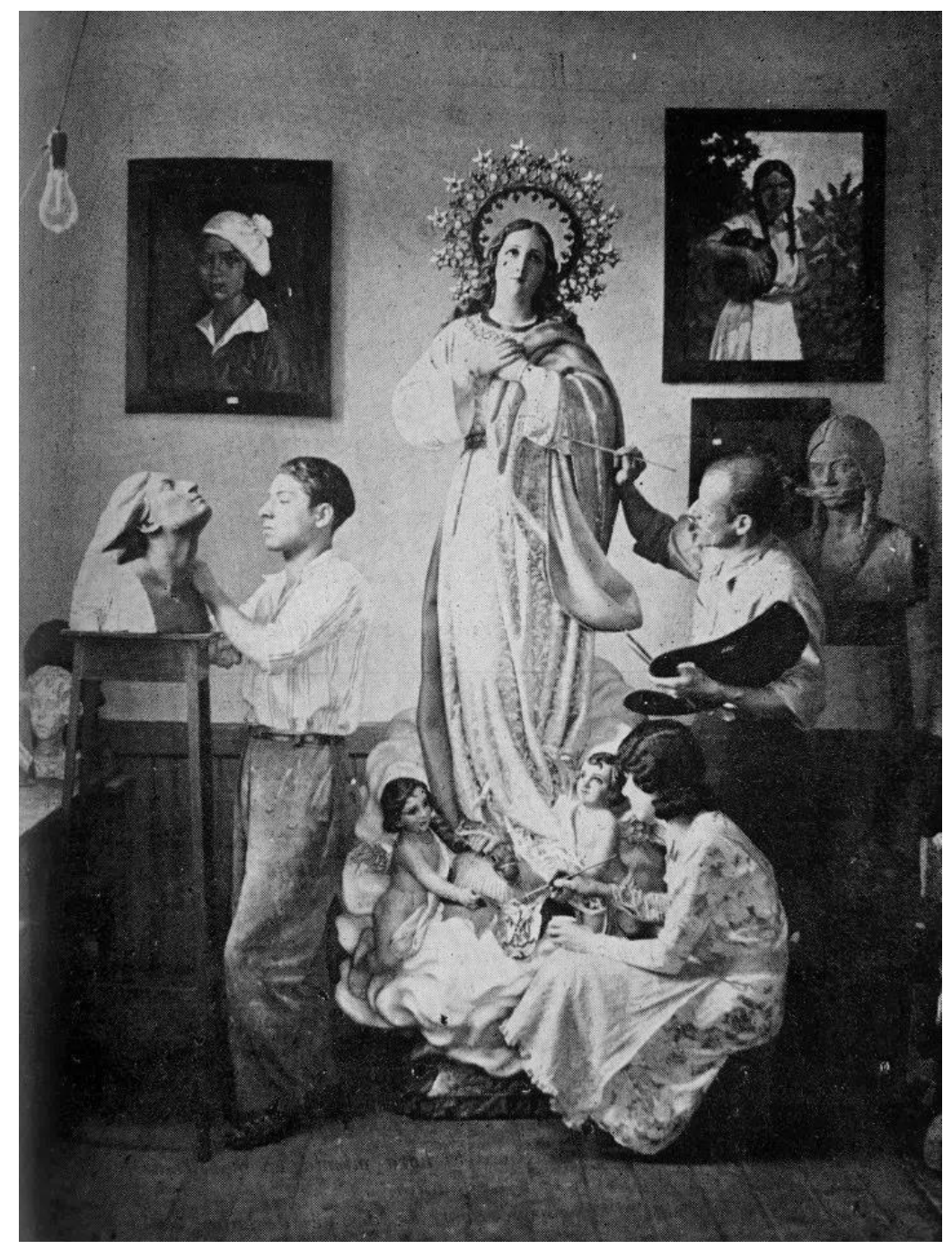

Figura N ${ }^{\circ}$ 1. Fotografía titulada "Familia de artistas", publicada el 22 de octubre de 1933 en el Eco Católico. Aparecen en torno a la imagen de la Inmaculada Concepción de Zapote, Manuel Zúñiga Rodríguez, al pie su hermana y a la izquierda su hijo Francisco con otra escultura confeccionada por este último. 


\section{La vida del artista como referente}

Manuel María Andrés Zúñiga Rodríguez, nació en San José el 3 de diciembre de 1890, bautizado el 7 de diciembre de 1890 en la iglesia del Carmen, según consta en el libro de Bautizos 80, folio 154, asiento 402, de dicha parroquia capitalina.

Hijo de Marcelo Zúñiga y Amelia Rodríguez. Se puede inferir que su familia fue muy cercana a la jerarquía eclesiástica costarricense, pues su hermano Carlos Manuel Francisco de Jesús de Las Mercedes, fue bautizado por Mons. Bernardo Augusto Thiel en la capilla del palacio arzobispal y el mismo Manuel tuvo por padrino al Pbro. Ricardo Zúñiga, quien también fuera familiar suyo.

En su familia se detecta la veta artística y se constata que desde temprana edad él se inició en el mundo de la plástica, aprendiendo las técnicas con su tío José Zúñiga y posteriormente con el arquitecto Luis Llach. No obstante, tal como señala el historiador Leoncio Jiménez:

\footnotetext{
"En la actualidad, con excepción de referencias aisladas, la obra y vida de este maestro imaginero, es prácticamente desconocida, aunque por diferentes motivos tuvo una participación decisiva en los movimientos escultóricos del país, tanto en escultura secular como religiosa." (2012, párr. 59).
}

Pese a que en el imaginario academicista de las artes y de las élites, que definen el valor cultural y económico de las obras artísticas, el concepto de imaginero o santero, se halla por debajo del concepto de artista, sin temor a error se puede afirmar que Manuel Zúñiga cumple con todo los atestados como artista; pero, en su caso, es imposible disociar sus habilidades como artista con su vida de fe.

Él, como auténtico artista sacro, ejerció su oficio mezclando los conocimientos técnicos y la creatividad, pese a los límites establecidos por el canon, con una meditación profunda de los dogmas de fe del cristianismo católico que él abrazaba. Esto se evidencia de manera privilegiada en un texto redactado por él, con respecto a la creación del Cristo de la Agonía o Señor de la Misericordia de la iglesia de la Merced, en el cual demuestra su estudio asiduo de los textos de la patrística y los ejercicios físicos y espirituales realizados para alcanzar la que es denominada su obra maestra. 
Sobre el proceso de creación de dicha imagen de Jesucristo, don Manuel escribió una defensa sobre las razones por las cuales colocó cuatro clavos en lugar de tres, al respecto dice:

Inspirándome en la Sacrificio del Divino Mtro. en la cruz, esculpí en cedro amargo de nuestros bosques del Guanacaste la imagen del Redentor, tal como creo sucedió su crucifixión con base deducida de la Sagrada Escritura y de escritos de Doctores de la Iglesia y de anatomistas. (Correo Nacional, 22 de junio de 1930).

Norma Loaiza, en la entrevista que le realizara poco tiempo antes de su muerte, logró establecer esa relación entre el hombre de las artes y el hombre de la fe cuando afirma que Zúñiga enseñó con su escultura religiosa a nuestros pueblos a orar (1978, p.10).

Esa relación entre el hombre de arte y el hombre de Iglesia, se hace evidente con el apoyo recibido por la institucionalidad eclesiástica que, en la voz de presbíteros como Ricardo Zúñiga o Rosendo Valenciano, le brindaron elogios y se estimuló en otros miembros del clero el encargo de obras sacras a su taller.

Asimismo, es fundamental contextualizar al escultor en una Costa Rica caracterizada por el fervor católico, cuya población demandaba, en el mercado de bienes religiosos, figuras referidas a los misterios de su fe. Todo ello potenciado con la erección de la diócesis de San José y la construcción de un mayor número de iglesias para una población cada vez más numerosa, distribuida en los nuevos cantones del Estado-nación configurado a partir de la segunda mitad del siglo XIX (Sandí, 201, p.61). Lo anterior se une a la demanda de las familias que requieren de las figuras de la sagrada familia y demás personajes bíblicos para preparar el portal navideño que, en el caso del autor que nos compete se ve refleja incluso en el trabajo realizado en el taller de su segunda esposa, doña Consuelo Sandoval.

\section{Las obras}

Todo artista, reconocido como tal, pasa por distintos estadios o fases creativas. Incluso en la imaginería, ámbito en el cual las temáticas están sumamente definidas por cánones eclesiásticos e imaginarios de las comunidades creyentes, el genio de los artistas se plasma en estilos y formas de resolver la composición. 
Según Reymundo Méndez, citado por Luis Ferrero, se pueden identificar dos tradiciones imagineras en el Valle Central de Costa Rica: una es la del Valle del Barva y otra la del Valle del Guarco (1998, p.27). Siguiendo la línea sanguínea de los imagineros, Manuel Zúñiga corresponde a la del Valle de Barva, pues su tío abuelo Lico Rodríguez, fue nieto, por línea materna de Fernando Jacobo Cruz Paniagua.

\section{Listado $\mathrm{N}^{0} 1$.}

Imaginería firmada o fechada en documentos de época

(Total: 44 esculturas)

\begin{tabular}{|c|c|c|}
\hline Época & Tema & Ubicación \\
\hline 1923 & Sagrado Corazón de Jesús & S. Trinidad, Bº México \\
\hline 1926 & N.S. de la Asunción & La Soledad, SJ \\
\hline 1926 & Santa Teresita del Niño Jesús & El Carmen, SJ \\
\hline 1928 & Dulce Nombre de Jesús & \multirow{2}{*}{ La Merced, SJ } \\
\hline 1928 & N.S. de la Merced & \\
\hline 1928 & Sagrado Corazón de Jesús & S. Pablo, Heredia \\
\hline 1928 & Santa Teresita del Niño Jesús & S. Teresita, Aranjuez \\
\hline 1930 & Señor de la Agonía o Misericordia & La Merced, SJ \\
\hline 1931 & N.S. de la Merced & Inmaculada, Heredia \\
\hline 1931 & Inmaculada Concepción de María & Inmaculada, Zapote \\
\hline 1932 & N.S. de los Dolores & \multirow{3}{*}{ S. Pedro, Montes de Oca } \\
\hline 1932 & Santa María Magdalena & \\
\hline 1932 & San Juan & \\
\hline 1932 & Sagrado Corazón de Jesús & S. Teresita, Aranjuez \\
\hline 1933 & $\begin{array}{c}\text { Crucifijo (Señor de la } \\
\text { Misericordia) }\end{array}$ & \multirow{4}{*}{ Los Ángeles, San Rafael, Heredia } \\
\hline 1933 & N.S. de los Dolores & \\
\hline 1933 & Santa María Magdalena & \\
\hline 1933 & San Juan & \\
\hline 1935 & Medalla Milagrosa & S. Teresita, Aranjuez \\
\hline 1937 & Dormición de la Virgen María & La Soledad, SJ \\
\hline 1937 & San Francisco de Paula & S. Isidro, Coronado \\
\hline
\end{tabular}




\begin{tabular}{|c|c|c|}
\hline Época & Tema & Ubicación \\
\hline 1939 & Santa Marta & S. Isidro, Coronado \\
\hline 1940 & San Pedro Apóstol & S. Pedro, Montes de Oca \\
\hline 1950 & Relieves de altar mayor & \multirow{3}{*}{$\begin{array}{c}\text { Inmaculado Corazón, S. Rafael } \\
\text { Abajo }\end{array}$} \\
\hline 1950 & Sagrado Corazón de Jesús & \\
\hline 1950 & Inmaculado Corazón de María & \\
\hline 1956 & San Antonio de Padua & Inmaculada, Zapote \\
\hline 1956 & Nuestro Señor Jesús de Petatlán & S. Rafael, Escazú \\
\hline 1960 & María Reina del Universo & María Reina, Pavas \\
\hline Desconocido & Dulce Nombre de Jesús & Dulce Nombre, La Pitahaya \\
\hline Desconocido & Conjunto de Calvario & La Soledad, SJ \\
\hline Desconocido & N.S. de Fátima & Gamalotillo 2, Turrubares \\
\hline Desconocido & María Reina del Universo & La Carpintera, La Unión \\
\hline Desconocido & Cristo Yacente & N.S. de los Desamparados \\
\hline Desconocido & Sagrado Corazón de Jesús & El Carmen, Goicoechea \\
\hline Desconocido & Inmaculada Concepción de María & \multirow{3}{*}{ S. Ignacio, Acosta } \\
\hline Desconocido & San José & \\
\hline Desconocido & San Ignacio de Loyola & \\
\hline Desconocido & Cristo Rey & S. Isidro, Heredia \\
\hline Desconocido & Jesús Nazareno & \multirow{2}{*}{ S. Juan, Tibás } \\
\hline Desconocido & Sagrado Corazón de Jesús & \\
\hline Desconocido & $\begin{array}{c}\text { Santa Margarita María de } \\
\text { Alacoque }\end{array}$ & S. Vicente, Moravia \\
\hline Desconocido & Sagrado Corazón de Jesús & Templo Votivo, SJ \\
\hline
\end{tabular}

De Zúñiga existen 44 imágenes en las iglesias arquidiocesanas que sin ninguna duda se puede afirmar que son del él. Existen otras 367 obras que pueden ser atribuidas a él y su taller dentro de la Arquidiócesis. De las cuales 98 obras corresponden a las estaciones del Vía Crucis de las iglesias de Piedades de Santa Ana, San Vicente de Moravia, Santiago del Monte en la Unión, Concepción de Zapote, Barreal, San Francisco y San Pablo de Heredia; 13 obras que 
corresponden a figuras animales y 14 a otros personajes bíblicos para la confección del portal navideño, 2 son representaciones de la Santísima Trinidad, una imagen de la posada, 5 trabajos en santos sepulcros, destacándose los de Guadalupe de Goicoechea, San Rafael y San Pablo de Heredia y los altares de las iglesias de San Rafael Debajo de Desamparados y la Inmaculada de Heredia.

Listado $\mathrm{N}^{\circ} 2$.

Imaginería de la figura de Jesucristo

(Total: 68 esculturas)

\begin{tabular}{|c|c|}
\hline Tema & Ubicación \\
\hline \multirow[t]{2}{*}{ Bautismo de Jesús } & S. Juan, Puriscal \\
\hline & S. Vicente, Moravia \\
\hline \multirow[t]{2}{*}{ Cristo Rey } & Catedral Metropolitana \\
\hline & Cristo Rey, $\mathrm{B}^{\circ}$ \\
\hline \multirow{2}{*}{$\begin{array}{l}\text { Cristo Sumo y Eterno } \\
\text { Sacerdote }\end{array}$} & N.S. de Luján, SJ \\
\hline & La Legua, Puriscal \\
\hline \multirow[t]{7}{*}{ Cristo Yacente } & Las Ánimas \\
\hline & S. Luis de Tolosa, Aserrí \\
\hline & El Carmen, Goicoechea \\
\hline & N.S. de Guadalupe, Goicoechea \\
\hline & Inmaculada, Zapote \\
\hline & S. Isidro, Heredia \\
\hline & S. Pablo, Heredia \\
\hline \multirow[t]{3}{*}{ Dulce Nombre de Jesús } & Dulce Nombre, Higuito, Desamparados \\
\hline & S. Francisco, Tabarcia, Mora \\
\hline & S. Bárbara, Pavas \\
\hline Ecce Homo & S. Catalina, Uruca \\
\hline \multirow[t]{5}{*}{ Jesús Nazareno } & Piedades, Santa Ana \\
\hline & Monserrat, Bello Horizonte \\
\hline & S. Pedro, Pedernal, Puriscal \\
\hline & Guayabos, Curridabat \\
\hline & S. Miguel, Desamparados \\
\hline \multirow[t]{5}{*}{ Niño Dios } & Catedral Metropolitana \\
\hline & N.S. de los Desamparados \\
\hline & S. Antonio, Escazú \\
\hline & S. Vicente, Moravia \\
\hline & N.S. del Sgdo. Corazón, Llorente, Tibás \\
\hline \multirow{4}{*}{$\begin{array}{l}\text { Nuestro Señor Jesús de } \\
\text { Petatlán }\end{array}$} & S. Juan de Dios, Desamparados \\
\hline & S. Miguel, Escazú \\
\hline & S. Agustín, Cinco Esquinas \\
\hline & N.S. de Ujarrás, B Córdoba \\
\hline
\end{tabular}




\begin{tabular}{|c|c|}
\hline Tema & Ubicación \\
\hline \multirow[t]{3}{*}{ Resucitado } & S. Vicente, Moravia \\
\hline & Guayabos, Curridabat \\
\hline & S. Pablo, Heredia \\
\hline \multirow{12}{*}{$\begin{array}{l}\text { Sagrado Corazón de } \\
\text { Jesús }\end{array}$} & Las Ánimas \\
\hline & Rectoría Medalla Milagrosa, Calle 20 \\
\hline & N.S. de los Desamparados \\
\hline & S. Agustín, Jericó \\
\hline & Piedades, Santa Ana \\
\hline & S. Pedro, Pedernal, Puriscal \\
\hline & Inmaculada, Grifo Alto \\
\hline & S. Miguel, Rancho Redondo \\
\hline & Hacienda Monte Redondo, Aserrí \\
\hline & S. Martín, Bustamante \\
\hline & S. Pedro, Montes de Oca \\
\hline & Los Ángeles, San Rafael,, Heredia \\
\hline Santa Faz & N.S. del Perpetuo Socorro \\
\hline \multirow[t]{9}{*}{ Señor Crucificado } & El Carmen, SJ \\
\hline & S. Bárbara, Pavas \\
\hline & N.S. de Guadalupe, Goicoechea \\
\hline & La Violeta, Frailes \\
\hline & S. Ramón, La Unión \\
\hline & Inmaculada, Zapote \\
\hline & Catedral Metropolitana \\
\hline & El Carmen, Goicoechea \\
\hline & S. Luis, S. Domingo, Heredia \\
\hline \multirow[t]{3}{*}{ Señor de la Agonía } & S. Antonio, Curridabat \\
\hline & S. Fco. De Dos Ríos \\
\hline & S. Pablo, Heredia \\
\hline \multirow[t]{8}{*}{ Señor del Huerto } & La Soledad, SJ \\
\hline & Las Ánimas \\
\hline & S. Bárbara, Pavas \\
\hline & Corazón de María, $\mathrm{B}^{\circ}$ Pinto \\
\hline & Inmaculada, Heredia \\
\hline & Getsemaní, Heredia \\
\hline & S. Martín, Bajo los Molinos \\
\hline & S. Pablo, Heredia \\
\hline Señor del Triunfo & S. Pablo, Heredia \\
\hline
\end{tabular}


Listado $N^{\circ} 3$.

Imaginería de la figura de Santa María Virgen

(Total: 72 esculturas)

\begin{tabular}{|c|c|}
\hline Tema & Ubicación \\
\hline $\begin{array}{l}\text { Dormición de la Virgen } \\
\text { María }\end{array}$ & Inmaculada, Zapote \\
\hline \multirow[t]{18}{*}{ Inmaculada Concepción } & Las Ánimas \\
\hline & N.S. del Perpetuo Socorro \\
\hline & La Dolorosa, SJ \\
\hline & Concepción, Alajuelita \\
\hline & S. Antoni, Desamparados \\
\hline & S. Pancracio, Huaso \\
\hline & Piedades, Santa Ana \\
\hline & Santiago, Puriscal \\
\hline & S. Pedro, Pedernal, Puriscal \\
\hline & El Carmen, Goicoechea \\
\hline & Natividad de la Virgen, La Uruca \\
\hline & S. Ignacio, Acosta \\
\hline & Ceiba Este, Acosta \\
\hline & S. Pedro, Montes de Oca \\
\hline & S. Joaquín, Cipreses, Curridabat \\
\hline & S. Fco. De Dos Ríos \\
\hline & S. Bartolomé, Barva \\
\hline & Los Ángeles, S. Domingo, Heredia \\
\hline \multirow[t]{2}{*}{ María Reina del Universo } & Rectoría Medalla Milagrosa, Calle 20 \\
\hline & María Reina, Hatillo 2 \\
\hline \multirow[t]{5}{*}{ Medalla Milagrosa } & Stma Trinidad, Hatillo 7 \\
\hline & $\mathrm{B}^{\circ} \mathrm{Cuba}$ \\
\hline & S. Juan de Puriscal \\
\hline & Jaris, Mora \\
\hline & S. Juan, Tibás \\
\hline \multirow[t]{3}{*}{ N.S. de Fátima } & Dulce Nombre, Higuito, Desamparados \\
\hline & Inmaculada, Zapote \\
\hline & Villas de Ayarco, Curridabat \\
\hline \multirow{2}{*}{$\begin{array}{l}\text { Ntra. Señora de la } \\
\text { Asunción }\end{array}$} & Asunción de María, Ciudad Colón \\
\hline & Guachipelín, Escazú \\
\hline \multirow[t]{3}{*}{ N.S. de la Merced } & Asunción de María, Ciudad Colón \\
\hline & S. Martín, Bajo los Molinos \\
\hline & S. Domingo, Heredia \\
\hline \multirow[t]{2}{*}{ N.S. de la Paz } & Junquillo Arriba \\
\hline & Granadilla, Curridabat \\
\hline
\end{tabular}




\begin{tabular}{|c|c|}
\hline Tema & Ubicación \\
\hline \multirow[t]{2}{*}{ N.S. de las Piedades } & Piedades, Santa Ana \\
\hline & Piedades, Puriscal \\
\hline N.S. de los Dolores & La Dolorosa, SJ \\
\hline N.S. de Ujarrás & N.S. de Ujarrás, B Córdoba \\
\hline \multirow[t]{16}{*}{ N.S. del Carmen } & El Carmen, SJ \\
\hline & El Carmen, SJ \\
\hline & Santo Cristo de Esquipulas, Alajuelita \\
\hline & El Carmen, Puriscal \\
\hline & El Carmen, Cortezal \\
\hline & S. Fco, Tabarcia, Mora \\
\hline & S. Vicente, Moravia \\
\hline & S. Vicente, Moravia \\
\hline & El Carmen, Goicoechea \\
\hline & S. Miguel, Rancho Redondo \\
\hline & S. Rafael, Calle Blancos \\
\hline & S. Juan, Tibás \\
\hline & Linda Vista, Tibás \\
\hline & N.S. del Carmen, Los Mangos \\
\hline & S. Martín, Bustamante \\
\hline & S. Rafael, Heredia \\
\hline \multirow[t]{5}{*}{ N.S. del Rosario } & Sagrado Corazón, B Iglesias Flores \\
\hline & Santiago, Puriscal \\
\hline & N.S. del Rosario \\
\hline & Inmaculada, Heredia \\
\hline & S. Isidro, Heredia \\
\hline \multirow[t]{2}{*}{ N.S. del Sagrado Corazón } & San Juan de Dios, Desamparados \\
\hline & N.S. del Sgdo. Corazón, Llorente, Tibás \\
\hline Virgen de la Alegría & Concepción, La Unión \\
\hline Virgen de Monserrat & López Mateo \\
\hline Virgen Niña & Piedades, Santa Ana \\
\hline \multirow[t]{6}{*}{ Virgen del Pesebre } & Catedral Metropolitana \\
\hline & N.S. de los Desamparados \\
\hline & S.Antonio, Escazú \\
\hline & S. Antonio Arriba, Puriscal \\
\hline & S. Vicente, Moravia \\
\hline & N.S. del Sgdo. Corazón, Llorente, Tibás \\
\hline
\end{tabular}


Listado $\mathrm{N}^{\circ} 4$.

Imaginería de la figura de santos y santas

(Total: 72 esculturas)

\begin{tabular}{|c|c|}
\hline Tema & Ubicación \\
\hline San Andrés apóstol & S.Andrés, León Cortés \\
\hline \multirow[t]{2}{*}{ San Antonio de Padua } & Salitral, Santa Ana \\
\hline & N.S. de los Ángeles, S. Cristóbal Sur \\
\hline \multirow[t]{2}{*}{ San Blas } & S. Blas, Moravia \\
\hline & S. Antonio, Curridabat \\
\hline San Cayetano & Inmaculada, Zapote \\
\hline San Francisco de Asís & S. Fco de Dos Ríos \\
\hline San Gabriel Arcángel & S. Gabriel, Montecito \\
\hline San Isidro Labrador & S. Pedro, Pedernal, Puriscal \\
\hline San Jerónimo & S. Jerónimo, Moravia \\
\hline \multirow[t]{3}{*}{ San Joaquín } & Concepción, Alajuelita \\
\hline & S. Joaquín, Río Oro, Santa Ana \\
\hline & S. Joaquín, La Palma \\
\hline \multirow[t]{15}{*}{ San José } & Las Ánimas \\
\hline & Rectoría Medalla Milagrosa, Calle 20 \\
\hline & N.S. de los Desamparados \\
\hline & S. Antonio, Escazú \\
\hline & S. Pedro, Pedernal, Puriscal \\
\hline & S. Isidro, Barbacoas \\
\hline & S. Fco, Tabarcia, Mora \\
\hline & Palmichal, Acosta \\
\hline & S. Vicente, Moravia \\
\hline & S. Isidro, Coronado \\
\hline & El Carmen, Goicoechea \\
\hline & Ceiba Este de Acosta \\
\hline & S. Pedro, Montes de Oca \\
\hline & Inmaculada, Zapote \\
\hline & S. Josecito, S. Rafael, Heredia \\
\hline \multirow[t]{3}{*}{ San José del Pesebre } & Catedral Metropolitana \\
\hline & S. Antonio Arriba, Puriscal \\
\hline & $\begin{array}{l}\text { Ntra. Señora del Sagrado Corazón, Llorente, } \\
\text { Tibás }\end{array}$ \\
\hline
\end{tabular}




\begin{tabular}{|c|c|}
\hline Tema & Ubicación \\
\hline \multirow[t]{3}{*}{ San José obrero } & S. José obrero, Paso Ancho \\
\hline & Inmaculado Corazón, S. Rafael Abajo \\
\hline & Cristo Rey, Vuelta de Jorco \\
\hline \multirow[t]{2}{*}{ San Juan Bautista } & S. Juan de Puriscal \\
\hline & S. Juan, La Unión \\
\hline San Juan de Dios & S. Juan de Dios, Desamparados \\
\hline \multirow[t]{3}{*}{ San Juan Evangelista } & Asunción de María, Ciudad Colón \\
\hline & S Juan, La Legua \\
\hline & Concepción, La Unión \\
\hline \multirow[t]{3}{*}{ San Judas Tadeo } & S. Rafael de Santa Ana \\
\hline & S. Marta, La Y Griega \\
\hline & S. Juan, Patarrá \\
\hline San Luis de Tolosa & S. Luis, Acosta \\
\hline San Nicolás de Bari & La Soledad, SJ \\
\hline \multirow[t]{3}{*}{ San Pablo Apóstol } & Catedral Metropolitana \\
\hline & S. Pablo, Turrubares \\
\hline & S. Pablo, Heredia \\
\hline San Pancracio & La Soledad, SJ \\
\hline \multirow[t]{6}{*}{ San Pedro Apóstol } & Catedral Metropolitana \\
\hline & S. Juan, Rincón Grande de Pavas \\
\hline & Asunción de María, Ciudad Colón \\
\hline & S. Pedro, Pedernal, Puriscal \\
\hline & Concepción, La Unión \\
\hline & Inmaculada, Zapote \\
\hline San Vicente de Paul & Piedades, Santa Ana \\
\hline San Vicente Ferrer & S. Vicente, Moravia \\
\hline San Vito (San Víctor) & S. Isidro, Coronado \\
\hline Santa Cecilia & El Carmen, SJ \\
\hline \multirow{3}{*}{$\begin{array}{l}\text { Santa Francisca Javiera } \\
\text { Cabrini }\end{array}$} & El Carmen, SJ \\
\hline & Templo Votivo, SJ \\
\hline & Piedades, Santa Ana \\
\hline $\begin{array}{l}\text { Santa Margarita de } \\
\text { Alacoque }\end{array}$ & Templo Votivo, SJ \\
\hline \multirow[t]{2}{*}{ Santa María Magdalena } & S. Vicente, Moravia \\
\hline & Inmaculada, Zapote \\
\hline
\end{tabular}




\begin{tabular}{l|l}
\hline \multicolumn{1}{c|}{ Tema } & \multicolumn{1}{c}{ Ubicación } \\
\hline \multirow{4}{*}{ Santa Marta } & El Carmen, SJ \\
\cline { 2 - 2 } & S. Vicente, Moravia \\
\cline { 2 - 2 } & S. Marta, La Y Griega \\
\cline { 2 - 2 } & Inmaculada, Heredia \\
\cline { 2 - 2 } $\begin{array}{l}\text { Santa Teresita del Niño } \\
\text { Jesús }\end{array}$ & S. Marta, La Legua, Aserrí \\
\hline Santiago Apóstol & S. Lucía, Barva \\
\hline
\end{tabular}

Listado № 5 .

Imaginería de la figura de ángeles

(Total: 20 esculturas)

\begin{tabular}{l|l}
\hline \multicolumn{1}{c}{ Tema } & \multicolumn{1}{c}{ Ubicación } \\
\hline \multirow{2}{*}{ San Rafael } & S. Rafael, Escazú \\
\cline { 2 - 2 } San Miguel & S. Rafael, Calle Blancos \\
\hline San Gabriel & La Merced, San José \\
\hline Ángel para agua bendita & S.S. de la Merced, San José \\
\hline \multirow{2}{*}{ Ángel de gloria para portal } & Catedral Metropolitana \\
\cline { 2 - 2 } & S. Teresita, Aranjuez \\
\cline { 2 - 2 } & N.S. de los Desamparados \\
\cline { 2 - 2 } & S. Antonio, Escazú \\
\hline \multirow{2}{*}{ Ángel de confortación } & Las Ánimas \\
\cline { 2 - 2 } & S. Pablo, Heredia \\
\hline \multirow{2}{*}{ Ángel de adoración } & S. Teresita, Aranjuez (3) \\
\cline { 2 - 2 } & N.S. de Guadalupe, Goicoechea (2) \\
\cline { 2 - 2 } & S. Ignacio, Acosta \\
\cline { 2 - 2 } & S. Isidro, Heredia (2) \\
\hline
\end{tabular}

Entre las obras confeccionadas está un santo Cura Ars, para la primera fiesta de los párrocos en su honoren San José de la Montaña, pero se desconoce dónde está (Eco Católico, 31/ enero / 1931). 
Muchas de las obras fueron donadas a las parroquias por feligreses, como es el caso de Alberto Obando con la Inmaculada de Zapote y el San Antonio de Padua de la misma parroquia donado por la familia Soto Harrison o el Sgdo. Corazón de Jesús donado por Carolina Dent, así como el Señor de la Misericordia de La Merced, donado por Clara Dawn Quesada.

\section{Las necesidades de investigación continúan}

La revisión detenida de todas las obras propiedad de la Iglesia Arquidiocesana, permitió determinar 402 esculturas del artista que nos compete, una cifra lejana de las 2000 referidas por el escultor a Norma Loaiza. Sin embargo, es pertinente anotar, a manera de conclusión, que existen muchas esculturas situadas en otras iglesias, familias e instituciones costarricenses, por ello con miras a plantear posibles investigaciones futuras y ampliar los hallazgos acá expuestos, enunciamos a continuación algunas de ellas.

Se identifican el retablo del altar de Nuestra Señora del Rosario en la iglesia de las Mercedes en Grecia, un San Gerardo en la iglesia de La Agonía y el santo patrono del cantón de San Mateo, lo anterior en la provincia de Alajuela; así como cuatro esculturas sobre la Sepultura del Señor ubicadas en la iglesia de Palmares, en el Museo Nuestra Señora de Ujarrás, en la capilla de Velación de la Catedral de Puntarenas y el cementerio de Chacarita en la misma provincia. El Cristo yacente de la iglesia del Carmen, en Cartago, un San Pablo apóstol de la Catedral de Limón y el portal de la catedral de Alajuela. También se cuenta el Sagrado Corazón del Mercado Central de San José, intervenido de manera abusiva en el 2017.

Destacables son los cuatro retablos referentes a la historia y devoción a la Virgen de Ujarrás, tallados en madera y únicos en su estilo, junto con los siete ángeles y el crucifijo dispuestos en el altar que se reconstruyó para dicha advocación mariana, y una Santa Marta, todo esto en el santuario de Paraíso, Cartago. El vasto y minucioso arte sacro de don Manuel merece cuidado y estudio, pues demuestra esmero en la técnica y en la teología detrás de cada una de sus representaciones plásticas del Misterio. 


\section{BIBLIOGRAFÍA}

\section{Libros}

Blanco, R. y Solera, A. (1963). Reseña Histórica de la Parroquia de Santa Teresita del Niño Jesús (Aranjuez). San José: Imprenta Metropolitana.

Chang, G. (2016). Acervo Turístico Cultural Costarricense. San José: EUNED.

El Mensajero del Clero. (Abril, 1939). Altar Mayor de la Iglesia Parroquial de Paraíso. Año XLIX ( $\left.{ }^{\circ} 4\right)$. Arquidiócesis de San José

Ferrero, L. (1998). Imaginería. Zeledón, E. (comp). (1998). El Santoral Costarricense. Fiestas y Tradiciones. San José: Editorial de la Universidad de Costa Rica. Pp. 11-36.

Fumero, A. (1998). Juan R. Chacón. San José: Editorial UCR.

Herrero, P. (1992). El Arte en la Evangelización. Memoria de la exhibición realizada en celebración del V Centenario de la Evangelización. MCJ - Curia Metropolitana.

Jiménez, L. (2012). Escultores costarricenses entre 18211950. Asociación para el Fomento de los Estudios Históricos en Centroamérica. Disponible en: http://afehc-historia-

centroamericana.org/index.php?action=fi_aff\&id $=30467$

Jiménez, L. (2013). La escultura en el estado de Costa Rica. Acta Académica (53), 69-100. UACA.

Le Franc, R. (1999). Parroquia de la Inmaculada Concepción de Zapote (Reseña histórica). Municipalidad de San José.

Loaiza, N. (1978). La abundancia y el tiempo. San José: EUNED.

Méndez, R. (1997). Lico Rodríguez. Escultor de imaginería religiosa. San José: EUNED. 
Parroquia San Rafael de Heredia. (1986). Celebración de nuestro centenario parroquial.

Parroquia María Reina del Universo. (1992). Reseña histórica de la parroquia. Rito solemne de la consagración del templo. Pavas.

Quirós, J. (1998). Capilla de Santa María N.S. de la Medalla Milagrosa. 50 Aniversario. San José: Ed. CECOR.

Rojas, J. (2003). Arte costarricense: un siglo. San José: Ed. Costa Rica.

\section{Revistas}

Bonilla, L. y Santamaría, L. (2016). Levantamiento del inventario de arte sacro, objetos destinados al culto y otras expresiones artísticas de la Arquidiócesis de San José. 2007-2014. Espiga. XV (32),103-118.

Sandí-Morales, A. (2011). La participación de la iglesia católica en el control del espacio en medio de la creación de un país llamado Costa Rica, 1850-1920. Revista de Historia. 63-64, 53-99. Disponible en: http://www.revistas.una.ac.cr/index.php/historia/article/view/4583

\section{Períodicos}

_ (2005). Restauración de la iglesia de La Merced. Experiencia organizativa y administrativa desarrollada por la Comisión de Restauración de la iglesia de la Merced. (Informe).

_ (22 de junio, 1930). Importante documento sobre la magnífica escultura del Santo Cristo en la Agonía del genial escultor don Manuel M. Zúñiga. Correo Nacional. P.1.

_ (7 de febrero, 1932). Conjunto escultórico del Señor de la Misericordia de San Pedro. Eco Católico. Portada.

_ (29 de mayo, 1932). Programa dela festividad y bendición de la nueva imagen del Sagrado Corazón de Jesús en la parroquia de Heredia. Eco Católico. p.80.

_(10 de julio, 1932). El B Iglesias Flores de Fiesta. Eco Católico. p.170. 
_ (9 de octubre, 1932). Solemne festividad del día de santa Teresita del Niño Jesús. Eco Católico. p.384.

_ (22 de agosto, 1937) "Una obra maestra del escultor nacional don Manuel Zúñiga" En: Eco Católico. pág. 121.

_ (23 de enero de 1944). Ante la Virgen de las Piedades. Eco Católico. p.66.

_(6 de julio, 1986). San Rafael de Heredia. 100 año parroquia. Eco Católico. pp.58.

Arrieta, V. (29 de abril de 1934). Nueva creación de don Manuel Zúñiga. Eco Católico. p.297.

Ávalos, Á. (21 de marzo, 2008). La Merced resucita. Revista Proa. La Nación. pp.12-15.

Camacho, C. (24 de junio, 2017). Rejuvenecen al Corazón de Jesús. La Teja.

Chinchilla, D. (23 de septiembre de 2012). Pecados contra el arte. Áncora, La Nación. p.4.

Delgado, W. (10 de septiembre, 1995). Templo y hombres signos de Cristo en Escazú. Eco Católico. p.6.

Fonseca, P. (21 de octubre, 2007). El renacer de la Merced. Áncora, La Nación. Disponible en: http://wvw.nacion.com/ancora/2007/octubre/21/ancora1250121.html

Fonseca, P. (23 de enero, 2010). Iglesia de la Merced invita a redescubrir sus tesoros. La Nación. p. 16A.

Loaiza, N. (2 de julio, 1978). Manuel María Zúñiga, el titán imaginero del siglo XX. Áncora, La Nación.

Monterrosa, M. (28 de marzo, 2010). Arte engalana la Semana Santa. Eco católico. p.12. 
Mora, E. (10 de noviembre, 1990). Santa Teresita: un estilo renacentista. La Prensa Libre.

Vargas, G. (1999). Iglesia de N.S. de la Merced. Ficha No 1-01-02-04. Centro de Investigación y Conservación del Patrimonio Cultural.

Vega, M. (5 de abril, 2009). Un sepulcro con más de 60 años. Al Día. Disponible en: http://wvw.aldia.cr/ad_ee/2009/abril/05/nacionales1919670.html

Zuñiga Salas, T. (23 de diciembre, 2007). Primeros pasos. Áncora, La Nación. pp. 6-7.

\section{Audiovisuales}

Delgado, M. (2011). Los herederos de Zúñiga. 7 Días. Disponible en: https://www.youtube.com/watch?v=r1c0-oCHwwO 
Revista Herencia, Vol. 31 (1), enero-junio, 2018. 